OPEN ACCESS

Edited by:

Gabriel Machovsky-Capuska,

University of Sydney, Australia

Reviewed by:

Rita P. Vasconcelos,

Universidade de Lisboa, Portugal Monica F. Costa,

Universidade Federal de Pernambuco,

Brazil

*Correspondence:

Jenny R. Hillman

j.hillman@auckland.ac.nz

Specialty section:

This article was submitted to

Marine Ecosystem Ecology,

a section of the journal

Frontiers in Marine Science

Received: 12 February 2018

Accepted: 21 September 2018

Published: 12 October 2018

Citation:

Hillman JR, Lundquist $C J$ and Thrush SF (2018) The Challenges Associated With Connectivity in

Ecosystem Processes.

Front. Mar. Sci. 5:364.

doi: 10.3389/fmars.2018.00364

\section{The Challenges Associated With Connectivity in Ecosystem Processes}

\author{
Jenny R. Hillman ${ }^{1 *}$, Carolyn J. Lundquist ${ }^{1,2}$ and Simon F. Thrush ${ }^{1}$ \\ ${ }^{1}$ Institute of Marine Science, University of Auckland, Auckland, New Zealand, ${ }^{2}$ National Institute of Water and Atmospheric \\ Research, Hamilton, New Zealand
}

Developing a framework to quantify the transformation, sequestration or connectivity of energy and matter across habitats is one of the most significant challenges faced by ecologists and resource managers today. However, there are significant challenges associated with quantifying the ecosystem processes that connect and interact across habitats. These processes include the movement of nutrients and energy and can have substantial effects on the structure and dynamics of adjacent habitats and ecosystem functioning. Here, we use a connectivity framework developed for populations to inform our understanding of the challenges associated with connectivity in ecosystem processes, and how specific habitats can contribute to overall ecosystem functioning. The landscape patterns and potential connections between habitats in terms of material storage or transformation have important implications for understanding how fragmentation and degradation of habitats in ecosystems will influence broad-scale ecosystem function.

\section{Keywords: connectivity, ecosystem function, ecosystem process, heterogeneity, population}

\section{INTRODUCTION}

Connectivity plays a central role in population dynamics in heterogeneous environments (Hanski, 2005). However, there are other dimensions to connectivity that are critical to many ecosystem functions (Polis et al., 1997). These dimensions include how resources are moved, transformed or stored within and between habitats. It was not until 1984 that the term "connectivity" was first defined in relation to environmental science (Merriam, 1984). Today the term encompasses a variety of fluxes in nature; population connectivity typically refers to the exchange of genes, propagules, larvae, sub-adult, and adult organisms, whereas aspects of ecosystem process-based connectivity include fluxes and sinks in energy, nutrients, and the propagation of disturbance effects. Frameworks that articulate replicable and pragmatic metrics of connectivity are vital as the interaction between processes and landscape features is increasingly recognised as an integral aspect of resource management plans (Calabrese and Fagan, 2004). Here we assess the suitability of the frameworks provided by population connectivity to identify the challenges and possible solutions associated with the patterns and connections between habitats via processes, and thus how ecosystems function and how their functionality changes with changes to habitats and connections between habitats.

To understand ecosystems connectivity, we require a currency with which to track energy and matter through the system, not only in terms of simple mass balance, but in terms of how processes interact. We define ecosystem functioning as the aspects of an ecosystem that influence their operation and provision of ecosystem services. Ecosystem functioning includes ecosystem 
processes (e.g., nutrient cycling, mineralisation), and properties of the ecosystem (e.g., resource use, standing biomass; Loreau et al., 2001). We define ecosystem services as the benefits people obtain from ecosystems, recognising that they are context-dependent and highly sensitive to income, technology, gender, culture, and geographical location (Millenium Ecosystem Assessment, 2005). The structure of patches and patch mosaics influences connections between populations and processes in different ways and at different spatial scales (Boström et al., 2011). Ecological interactions that occur within patches and among different types of patches are also critically important in supporting primary and secondary production, trophic transfer, biodiversity, and protection (Loreau et al., 2003). A habitat refers to an area with particular contributions to ecosystem processes. Habitats can be defined by physical and biological features (ecosystem engineers), and the level of variability within these habitat features can also be a defining characteristic (Diaz et al., 2004).

Extrapolating and generalising spatial relationships between ecological patterns and processes across scales remains a challenge and is a crucial aspect of managing and responding to an inevitably changing environment (Boström et al., 2011). Human activities, as well as an increasingly variable climate, have affected the capacity of ecosystems to maintain their function (Smit et al., 2000). Fragmentation, degradation and loss of habitats alter all the components of ecosystem service provision through changes in the matrix within which ecosystem processes are transferred between habitats within an ecosystem. To manage these systems, we therefore need to understand how changes in environmental and human drivers impact both habitat fragmentation and degradation, and their associated faunal and floral communities, to determine impacts on exchanges of fluxes and materials that are essential to maintaining ecosystem function (Braeckman et al., 2014; Mitchell et al., 2015).

\section{THE EXISTING-POPULATION CONNECTIVITY FRAMEWORKS}

Population connectivity frameworks have the potential to be used to develop new insights into process-based connectivity and ecosystem function. Dispersal mechanisms are important in determining species distributions across habitat patches, and seascape genetics have shown that a variety of forces impact connectivity at distinct spatio-temporal scales. GIS data and genomic scale sequencing illuminate differences between demographic, functional and neutral genetic connectivity (Selkoe et al., 2016). The scale of the landscape and connectivity of patches of organisms varies between species, between different life stages within species, and with differing environmental settings. Recent advances in landscape genetics, mechanistic dispersal modelling and ecological network analysis has shown that studies of the dispersal of both propagules and pollen by biotic or abiotic vectors must include the production of seeds and pollen at the source patch as well as the successful establishment of new individuals at the recipient patch (Auffret et al., 2017). Many organisms utilise wind, water and animal transport as long-distance dispersal mechanisms (Muñoz et al., 2004). In marine systems there is the potential for a high level of population connectivity as a result of pelagic/planktonic larval dispersal (Cowen et al., 2007). Larvae of marine organisms are not simply passively dispersed by water current, but can control their depth and thus direction, and these capabilities can increase with body size (Cowen and Sponaugle, 2009). Non-planktonic larval dispersal is also common, particularly in soft-sediment systems, with crawling and brooded larvae dispersing only short distances from the site of initial release (Grantham et al., 2003). Macroalgae population connectivity measures have shown that ignoring fluctuations in fecundity may overestimate connectivity, highlighting the need to include the fecundity, dispersal, recruitment, and survival of target species (Castorani et al., 2017). Postsettlement dispersal occurs in many taxa, via the bedload and in the water column (Pilditch et al., 2015). Adult movement is used by species in all taxon groups, with dispersal and connectivity dependent on mobility (Brückmann et al., 2010).

Population connectivity frameworks describe connectivity patterns of landscapes, allowing inferences about how changes in landscape patterns (i.e., presence, quantity, quality, and configuration of habitat types) influence the exchange of individuals of different life stages, and the possible feedbacks between scale of dispersal and persistence of a population. Individual life histories interact with landscape patterns to determine the scale of the landscape experienced by an organism, and how changes in landscape features and patterns influence population persistence. In a dynamic landscape, habitat patches have a finite lifetime and the linkage or connectivity between specific habitats may decrease with time, reducing habitat continuity and increasing fragmentation. The disappearance of patches increases the rate of local extinction, while a reduced amount of linked habitat decreases the rate of colonisation and thereby makes metapopulation persistence more difficult (Hanski, 1999). Knowledge of habitat heterogeneity is therefore an important management tool for maintenance of biodiversity (Hewitt et al., 2004).

Habitats can be defined by their heterogeneity, rather than the homogenous domination by individual species or sediment type. Heterogeneity refers to any variation in a habitat that is related to the relative abundance of any structural components (Bell et al., 1991). Habitat structure may be so intertwined with other components of the environment that documentation of its unique effect upon the organism(s) of interest is difficult (Bell et al., 1991). Both metapopulation and metacommunity studies highlight the importance of connectivity in terms of the movement of structure formers and the implications of these movements for system heterogeneity (e.g., Loreau and Mouquet, 1999). We can utilise these concepts to inform our understanding of how specific habitats contribute to ecosystem function in terms of functional performance, the degree to which they sequester or release energy or matter that affect the supply and flow of ecosystem services, and how this changes with landscape fragmentation and degradation. 


\section{THE CHALLENGES IN PROCESS CONNECTIVITY}

Many ecosystems are defined by multiple processes occurring over multiple temporal and spatial scales, with processes varying between habitats and their associated biotic community. This complexity requires a framework to enable us to determine ecosystem functioning, particularly with respect to addressing impacts of future changes. Loreau et al. (2003) expanded the concept of meta-community dynamics to include the movement of propagules, migrants, nutrients and energy under the framework of meta-ecosystems. However, it is difficult to practically assess ecosystem connectivity for ecosystem processing (see Table 1). The use of multiple drivers is important as the interactions among processes, communities and habitats are complex; a single factor alone cannot adequately describe a system in terms of multiple functions and ecosystem services. Once the source-sink nature of particular habitats has been empirically characterised in terms of connectivity of key processes or functions, empirical data reflecting multiple ecosystem processes can be combined to investigate how different habitats are connected (e.g., Figure 1).

There have been few empirical tests of process connectivity in a meta-ecosystem framework (see Loreau and Holt, 2004; Gravel et al., 2010a,b; Massol et al., 2011; Menge et al., 2015), and further developments are needed to be able to use this framework to understand heterogeneous ecosystems. Previous research into ecosystem process connectivity has focussed on tracking material and energy through an ecosystem, similar to early larval movement studies. Following particulate matter is more difficult than following larvae (though this is not easy!), as it is often much smaller (e.g., mud grains), and often cannot be tracked using modern techniques such as DNA fingerprinting (e.g., Almany et al., 2017). Instead techniques include, for example, the use of turbidity plumes and aerial images to ground-truth particle or particulate dispersion models. Inferring connectivity patterns with particulate tracers has had some success, but there are assumptions made with these methods, particularly as they are often based on limited empirical measurements that are unlikely to incorporate the range of typical diurnal, seasonal, climate, and storm-related variability that influences dispersal trajectories. Advances have been made in model frameworks for tracking larvae, which have led to advances in particle and sediment tracking models, but it is crucial that these models are validating using empirical data to confirm that they realistically predict how particulate matter will behave, and to generalise across hydrodynamic scenarios.

The composition of the faunal and floral communities in a meta-ecosystem framework also influences the flux of materials and energy. Species dominance in a community can directly influence a particular process (e.g., nutrient efflux, sediment stability), for example, through movement or feeding activity that is tightly coupled to the interactions within a community based on individual species' functional traits (Kristensen et al., 2014). This coupling is important for understanding changes in ecosystem functioning, as ecosystems experience change due to anthropogenic impacts which often directly influence community composition. Ecosystems collectively determine the biogeochemical processes that regulate the Earth's system as a whole, so biological communities have the potential to buffer or exacerbate global change (Cardinale et al., 2006; Davies et al., 2012). Furthermore, ecosystem process studies should incorporate multiple functional traits, rather than just one aspect such as size, as the largest species do not always have the greatest impact on ecosystem functioning (Solan et al., 2004). The results of human pressures on a community are not random; instead the sequence of species losses depends on the functional traits of the organisms and the mechanisms associated with how specific stressors affect species. Localised extinction rates will continue to accelerate into the next century (Snelgrove et al., 2014), so for the environment to be sustainably managed we need to be able to predict the potential impacts of large-scale environmental changes and the ecosystem consequences of altered biodiversity in order to effectively direct management and policy.

Through material and energy exchanges, ecosystem changes at a local scale can influence adjacent areas, and these effects can be extrapolated to regional and global scales (Arndt et al., 2013). Thus, habitat maps at scales that allow for interpretation of source-sink dynamics and quantification of ecosystem function are essential building blocks for meta-ecosystem models. However, resources are unlikely to be sufficient to empirically monitor each habitat at the temporal and spatial scales required to inform a meta-ecosystem framework. Rather, extrapolations of habitats using models to assess ecosystem predictors across space have become important. In heterogeneous systems, habitats are likely to differ in the degree to which they sequester and/or transform materials, or enhance transport rates, linking to the concepts of source/sink dynamics, whereby habitat patches serve as either sources or sinks in terms of the production of propagules. The general definition of the source and sink concept was developed to transcend disciplines and is based on net flows between the components of a system. This concept is contextdependent, but a source is a subsystem that is a net exporter of the entity of interest (living or non-living), and a sink is a net importer of these entities (Loreau et al., 2013). Population and process-based dynamics may not correspond in space, and patches may serve as sinks in terms of population dispersal (i.e., a retention zone for larval settlement), but as sources of processes (i.e., hotspots of primary production and nutrient cycling). Variability in spatial structure both within and between habitats is therefore an important functional component of a landscape, influencing not only population and community dynamics, but also the nature and efficiency of ecosystem processes (Legendre, 1993).

Subsidies represent the movement from a resource-rich location to a poorer location, and thus relate clearly to the concepts of source-sink dynamics in meta-population dynamics (Loreau and Holt, 2004). When a new subsidy is introduced into a system, the organisms and processes that rely on the subsidised resource increase as the ecosystem processes and community structure respond to the available resources (Polis et al., 1997). Spatial subsidies can be episodic but result in a legacy in the sink system, such as in the case of whale-falls or deposition of plant debris to the food-limited deep-sea floor, yielding pulses of 


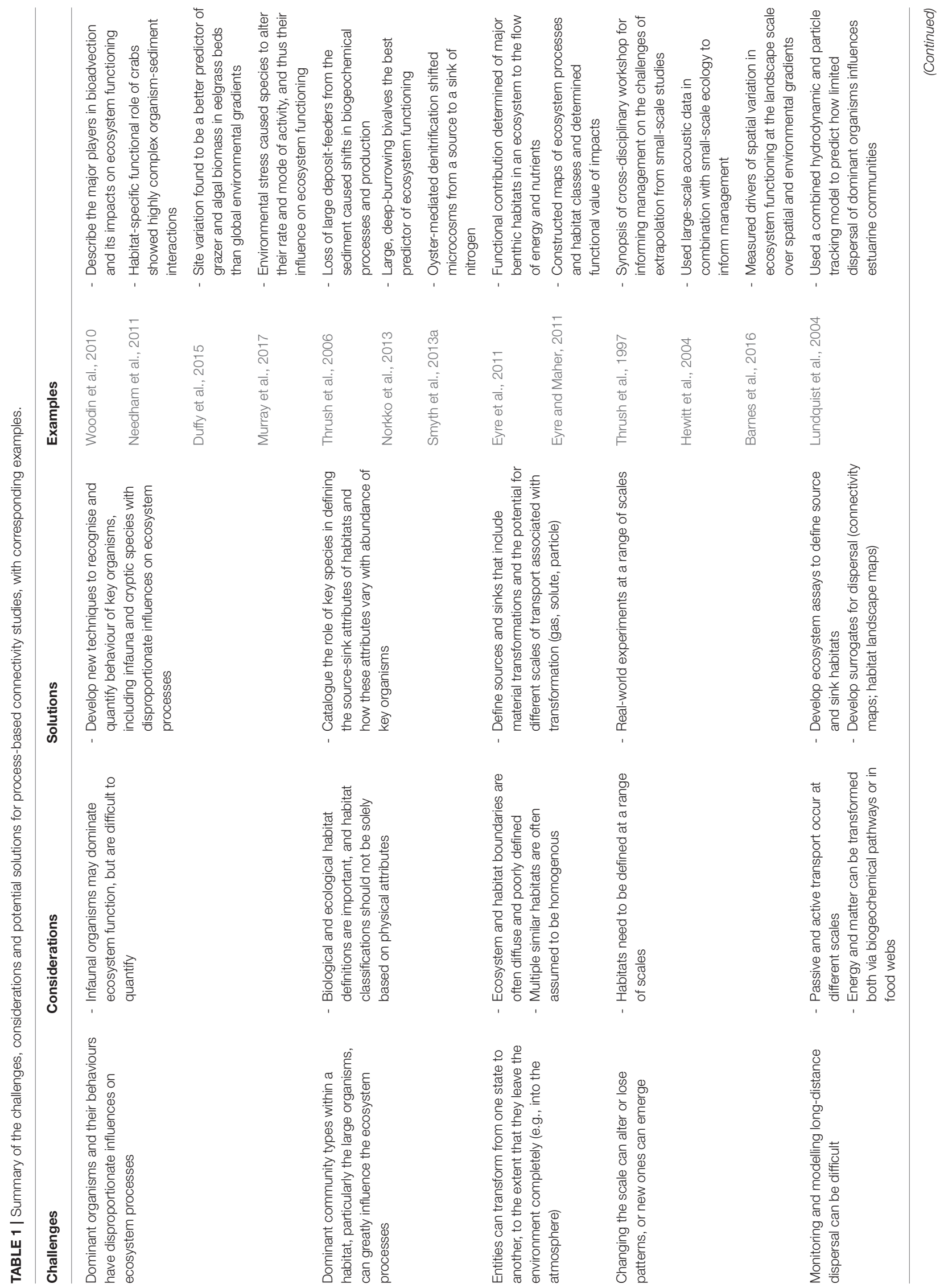




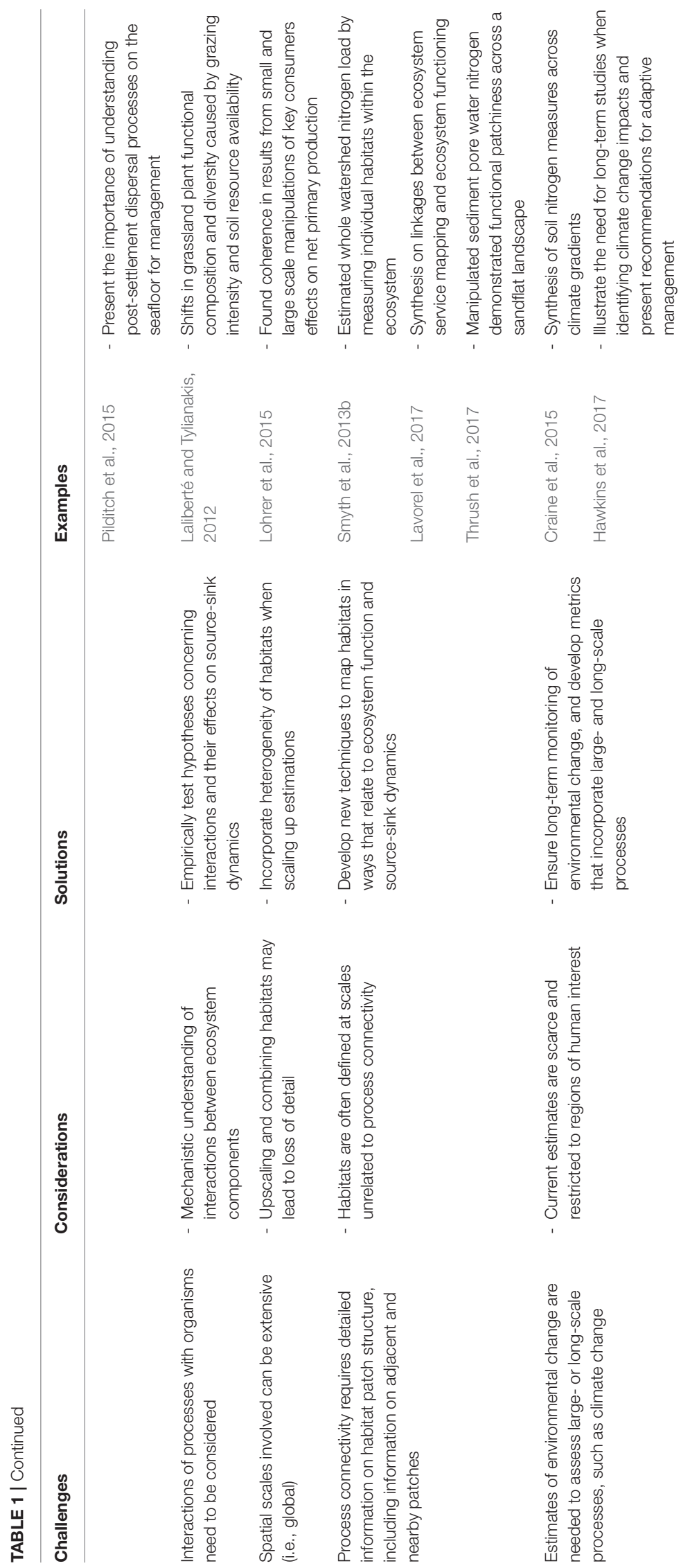




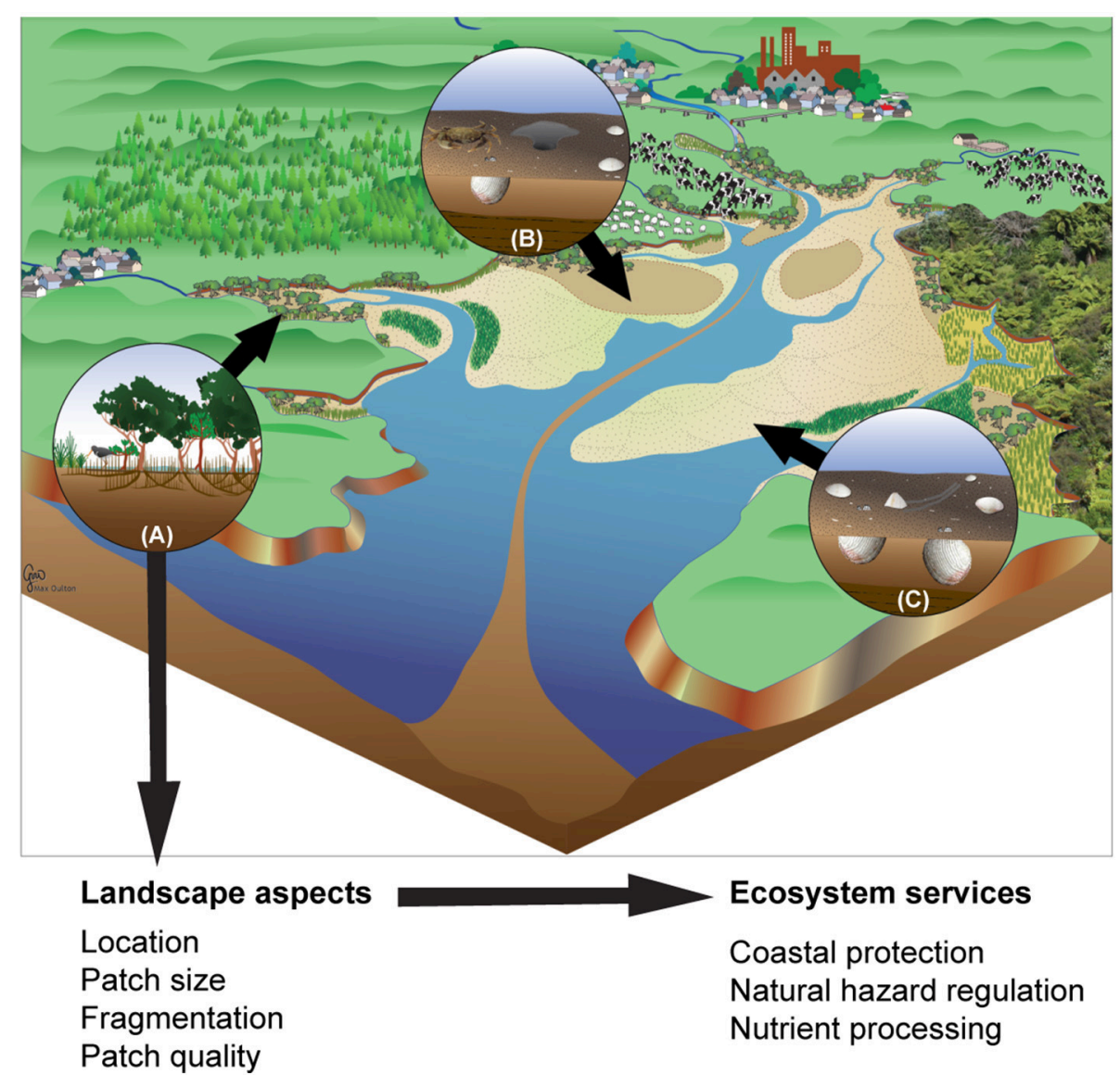

FIGURE 1 | Estuarine habitats that vary in their role in sequestering or exporting materials. Fine sediments are sequestered in mangroves (A), sediment erosion rates are increased by crab burrows in sandy sediments $\mathbf{( B )}$, and the rate of organic matter transformation and the remineralisation of nutrients are enhanced by the activities of infaunal bivalves (C). These processes serve to connect habitats by moving material between habitats within the estuary and the surrounding areas. Examples of the connectivity factors and ecosystem services are shown, highlighting not only the performance of specific habitats but also how the arrangement of the habitats within the estuary may influence the effective functioning and service delivery at the scale of the estuary.

labile organic matter and energy (Lundsten et al., 2010). These linkages help to define the nature of ecosystem functions and the level of functional performance at multiple spatial scales and, when supporting humans in the ecosystem, provide ecosystem services. However, whilst these allochthonous subsidies show the unidirectional flows between habitats, understanding the full extent of the multidirectional fluxes requires integration of more complex interactions between ecology and landscape elements.

In the most general sense, connectivity represents the flux of energy or matter, dissolved or particulate, and the changes that can occur as these components move through, or are stored or transformed in habitats. For example, dissolved nutrients can turn into particulate plant matter and then be remineralised due to the behaviour of organisms or via biogeochemical reactions that occur in either the sediment or the water column. At the habitat scale a patch may be a source or a sink of a specific magnitude, but patches are additionally coupled by the multi-directional flow of propagules, energy and matter, each in turn influencing ecosystem functionality. Extrapolating to the landscape scale; fragmentation and degradation of habitats results in non-linear decreases in patch connectivity and collapse of process linkages that contribute to ecosystem function (Debinski and Holt, 2000). This spatial heterogeneity produced as a result of local disturbance events also influences the structure and function of benthic communities, and thus determines the recovery potential of both ecosystem structure and function (Thrush and Dayton, 2002).

\section{CONCLUSIONS}

Whilst methods for measuring population connectivity continue to advance, substantial challenges remain in elucidating generalisations about process-based connectivity at the scale of ecological habitats. The complexity of the processes involved, as well as the need to quantify ecosystem function on multiple temporal and spatial scales, provide numerous areas for future research (Table 1). However, the methods developed in population connectivity research can serve as a useful building block for further development of process connectivity. The "meta-ecosystem concept" provides one conceptual framework 
to inform our understanding of ecosystem connectivity in the form of energy and matter (Loreau et al., 2003). However, the meta-ecosystem concept has been difficult to empirically operationalise. A simpler source-sink approach can be extrapolated across multiple processes and habitat patches, providing a more tractable framework to allow for empirical validation of theoretical concepts. The performance of the system can be altered along multiple dimensions reflecting both different processes and functions, and interactions with dominant community types that populate each habitat (Loreau and Holt, 2004). When impacts of system disturbances are considered, the hotspots of functionality across multiple processes can shift, and the system may become less effective at supporting ecosystem function (Thrush et al., 2017).

Natural ecosystems are moulded by ecological and environmental processes, which make them inherently complex on multiple temporal and spatial scales. We are only just beginning to realise the importance of how these processes interrelate with local species interactions to control the structure and function of meta-ecosystems (Gravel et al., 2010a). Increased spatial subsidies, due to regional climatic or anthropogenic factors, have been shown to affect the health and structure of interconnected ecosystems (Spiecker et al., 2016). The impact of source-sink dynamics associated with ecosystem functions such as nutrient cycling and sediment transport differ depending on the context, the associated habitats, and the entity in question, all of which must be accounted for when using the source-sink concept. There is clearly a need to understand how habitat structure changes may affect the functioning of an ecosystem, in association with anthropogenic impacts. This will lead to understanding of the implications at a system scale, encompassing change both within and across habitats.

\section{REFERENCES}

Almany, G. R., Planes, S., Thorrold, S. R., Berumen, M. L., Bode, M., SaenzAgudelo, P., et al. (2017). Larval fish dispersal in a coral-reef seascape. Nat. Ecol. Evol. 1:0148. doi: 10.1038/s41559-017-0148

Arndt, S., Jørgensen, B. B., LaRowe, D. E., Middelburg, J., Pancost, R., and Regnier, P. (2013). Quantifying the degradation of organic matter in marine sediments: a review and synthesis. Earth-Sci. Rev. 123, 53-86. doi: 10.1016/j.earscirev.2013.02.008

Auffret, A. G., Rico, Y., Bullock, J. M., Hooftman, D. A., Pakeman, R. J., Soons, M. B., et al. (2017). Plant functional connectivity-integrating landscape structure and effective dispersal. J. Ecol. 105, 1648-1656. doi: 10.1111/1365-2745.12742

Barnes, A. D., Weigelt, P., Jochum, M., Ott, D., Hodapp, D., Haneda, N. F., et al. (2016). Species richness and biomass explain spatial turnover in ecosystem functioning across tropical and temperate ecosystems. Phil. Trans. R. Soc. B 371:20150279. doi: 10.1098/rstb.2015.0279

Bell, S., McCoy, E. D., and Mushinsky, H. R. (1991). Habitat Structure: the Physical Arrangement of Objects in Space. Dordrecht: Springer Science \& Business Media.

Boström, C., Pittman, S. J., Simenstad, C., and Kneib, R. T. (2011). Seascape ecology of coastal biogenic habitats: advances, gaps, and challenges. Mar. Ecol. Prog. Ser. 427, 191-217. doi: 10.3354/meps09051

Braeckman, U., Rabaut, M., Vanaverbeke, J., Degraer, S., and Vincx, M. (2014). Protecting the commons: the use of subtidal ecosystem engineers in marine management. Aquat. Conserv. Mar. Freshw. Ecosyst. 24, 275-286. doi: 10.1002 aqc. 2448

Brückmann, S. V., Krauss, J., and Steffan-Dewenter, I. (2010). Butterfly and plant specialists suffer from reduced connectivity in fragmented
The effectiveness of reserves and the optimal spatial management of meta-ecosystems is important for resource managers to consider how to balance the multitude of ecosystem services in light of the increasing threats these systems face. Developing a fundamental understanding of the patterns and connections that exist between habitats via processes will lead to key insights into how ecosystems function and how changes in function are linked to changes in habitats and habitat connectivity. Filling this gap in our knowledge is crucial as it will allow for better mapping of ecosystem services, better understanding of the functional implications of habitat loss and fragmentation, and how breaking these connections impacts on ecosystem functionality.

\section{AUTHOR CONTRIBUTIONS}

All authors listed have made a substantial, direct and intellectual contribution to the work, and approved it for publication.

\section{ACKNOWLEDGMENTS}

We thank J. Stachowicz and J. Hewitt for helpful comments on earlier drafts of the manuscript. JH acknowledges funding from the New Zealand Ministry of Business, Innovation and Employment (National Institute of Water and Atmospheric Research Coasts \& Oceans Research Programme, Project COME1601) and the George Mason Charitable Trust (Travel Award 2015). This paper constitutes the first chapter of the doctoral thesis of $\mathrm{JH}$, which can be found online at the University of Auckland (Hillman, 2018).

landscapes. J. Appl. Ecol. 47, 799-809. doi: 10.1111/j.1365-2664.2010. 01828.x

Calabrese, J. M., and Fagan, W. F. (2004). A comparison-shopper's guide to connectivity metrics. Front. Ecol. Environ. 2, 529-536. doi: 10.1890/15409295(2004)002[0529:ACGTCM]2.0.CO;2

Cardinale, B. J., Srivastava, D. S., Duffy, J. E., Wright, J. P., Downing, A. L., Sankaran, M., et al. (2006). Effects of biodiversity on the functioning of trophic groups and ecosystems. Nature 443:989. doi: 10.1038/nature 05202

Castorani, M. C., Reed, D. C., Raimondi, P. T., Alberto, F., Bell, T. W., Cavanaugh, K. C., et al. (2017). Fluctuations in population fecundity drive variation in demographic connectivity and metapopulation dynamics. Proc. R. Soc. B 284:20162086. doi: 10.1098/rspb.2016.2086

Cowen, R. K., Gawarkiewicz, G. G., Pineda, J., Thorrold, S. R., and Werner, F. E. (2007). Population connectivity in marine systems: an overview. Oceanography 20, 14-21. doi: 10.5670/oceanog.2007.26

Cowen, R. K., and Sponaugle, S. (2009). Larval dispersal and marine population connectivity. Ann. Rev. Mar. Sci. 1, 443-466. doi: 10.1146/annurev.marine.010908.163757

Craine, J. M., Elmore, A. J., Wang, L., Augusto, L., Baisden, W. T., Brookshire, E., et al. (2015). Convergence of soil nitrogen isotopes across global climate gradients. Sci. Rep. 5:8280. doi: 10.1038/srep 08280

Davies, N. B., Krebs, J. R., and West, S. A. (2012). An Introduction to Behavioural Ecology. Chichester: John Wiley \& Sons.

Debinski, D. M., and Holt, R. D. (2000). A survey and overview of habitat fragmentation experiments. Conserv. Biol. 14, 342-355. doi: 10.1046/j.1523-1739.2000.98081.x 
Diaz, R. J., Solan, M., and Valente, R. M. (2004). A review of approaches for classifying benthic habitats and evaluating habitat quality. J. Environ. Manage. 73, 165-181. doi: 10.1016/j.jenvman.2004.06.004

Duffy, J. E., Reynolds, P. L., Boström, C., Coyer, J. A., Cusson, M., Donadi, S., et al. (2015). Biodiversity mediates top-down control in eelgrass ecosystems: a global comparative-experimental approach. Ecol. Lett. 18, 696-705. doi: 10.1111/ele.12448

Eyre, B. D., Ferguson, A. J., Webb, A., Maher, D., and Oakes, J. M. (2011). Metabolism of different benthic habitats and their contribution to the carbon budget of a shallow oligotrophic sub-tropical coastal system (southern Moreton Bay, Australia). Biogeochemistry 102, 87-110. doi: 10.1007/s10533-010-9424-7

Eyre, B. D., and Maher, D. (2011). Mapping ecosystem processes and function across shallow seascapes. Cont. Shelf Res. 31, S162-S172. doi: 10.1016/j.csr.2010.01.013

Grantham, B. A., Eckert, G. L., and Shanks, A. L. (2003). Dispersal potential of marine invertebrates in diverse habitats. Ecol. Appl. 13, 108-116. doi: 10.1890/ 1051-0761(2003)013[0108:DPOMII]2.0.CO;2

Gravel, D., Guichard, F., Loreau, M., and Mouquet, N. (2010a). Source and sink dynamics in meta-ecosystems. Ecology 91, 2172-2184. doi: 10.1890/09-0843.1

Gravel, D., Mouquet, N., Loreau, M., and Guichard, F. (2010b). Patch dynamics, persistence, and species coexistence in metaecosystems. Am. Nat. 176, 289-302. doi: $10.1086 / 655426$

Hanski, I. (1999). Habitat connectivity, habitat continuity, and metapopulations in dynamic landscapes. Oikos 87, 209-219. doi: 10.2307/3546736

Hanski, I. (2005). The Shrinking World: Ecological Consequences of Habitat Loss. Oldendorf/Luhe: International Ecology Institute.

Hawkins, S. J., Evans, A. J., Mieszkowska, N., Adams, L. C., Bray, S., Burrows, M. T., et al. (2017). Distinguishing globally-driven changes from regional-and localscale impacts: the case for long-term and broad-scale studies of recovery from pollution. Mar. Pollut. Bull. 124, 573-586. doi: 10.1016/j.marpolbul.2017.01.068

Hewitt, J. E., Thrush, S., Legendre, P., Funnell, G., Ellis, J., and Morrison, M. (2004). Mapping of marine soft-sediment communities: integrated sampling for ecological interpretation. Ecol. Appl. 14, 1203-1216. doi: 10.1890/03-5177

Hillman, J. R. (2018). Habitat Variability and Ecosystem Processes in Intertidal Soft-sediments [dissertation]. Auckland: The University of Auckland.

Kristensen, E., Delefosse, M., Quintana, C. O., Flindt, M. R., and Valdemarsen, T. (2014). Influence of benthic macrofauna community shifts on ecosystem functioning in shallow estuaries. Front. Mar. Sci. 1:41. doi: $10.3389 /$ fmars.2014.00041

Laliberté, E., and Tylianakis, J. M. (2012). Cascading effects of long-term landuse changes on plant traits and ecosystem functioning. Ecology 93, 145-155. doi: 10.1890/11-0338.1

Lavorel, S., Bayer, A., Bondeau, A., Lautenbach, S., Ruiz-Frau, A., Schulp, N., et al. (2017). Pathways to bridge the biophysical realism gap in ecosystem services mapping approaches. Ecol. Indic. 74, 241-260. doi: 10.1016/j.ecolind.2016.11.015

Legendre, P. (1993). Spatial autocorrelation: trouble or new paradigm? Ecology 74, 1659-1673.

Lohrer, A. M., Thrush, S. F., Hewitt, J., and Kraan, C. (2015). The upscaling of ecosystem functions in a heterogeneous world. Nature 5:10349. doi: $10.1038 /$ srep 10349

Loreau, M., Daufresne, T., Gonzalez, A., Gravel, D., Guichard, F., Leroux, S. J., et al. (2013). Unifying sources and sinks in ecology and Earth sciences. Biol. Rev. 88, 365-379. doi: 10.1111/brv.12003

Loreau, M., and Holt, R. D. (2004). Spatial flows and the regulation of ecosystems. Am. Nat. 163, 606-615. doi: 10.1086/382600

Loreau, M., and Mouquet, N. (1999). Immigration and the maintenance of local species diversity. Am. Nat. 154, 427-440. doi: 10.1086/303252

Loreau, M., Mouquet, N., and Holt, R. D. (2003). Meta-ecosystems: a theoretical framework for a spatial ecosystem ecology. Ecol. Lett. 6, 673-679. doi: 10.1046/j.1461-0248.2003.00483.x

Loreau, M., Naeem, S., Inchausti, P., Bengtsson, J., Grime, J. P., Hector, A., et al. (2001). Biodiversity and ecosystem functioning: current knowledge and future challenges. Science 294, 804-808. doi: 10.1126/science. 1064088

Lundquist, C. J., Thrush, S. F., Oldman, J. W., and Senior, A. K. (2004). Limited transport and recolonization potential in shallow tidal estuaries. Limnol. Oceanogr. 49, 386-395. doi: 10.4319/lo.2004.49.2.0386
Lundsten, L., Schlining, K. L., Frasier, K., Johnson, S. B., Kuhnz, L. A., Harvey, J. B. J., et al. (2010). Time-series analysis of six whale-fall communities in Monterey Canyon, California, USA. Deep Sea Res. Part I Oceanogr. Res. Papers 57, 1573-1584. doi: 10.1016/j.dsr.2010.09.003

Massol, F., Gravel, D., Mouquet, N., Cadotte, M. W., Fukami, T., and Leibold, M. A. (2011). Linking community and ecosystem dynamics through spatial ecology. Ecol. Lett. 14, 313-323. doi: 10.1111/j.1461-0248.2011.01588.x

Menge, B. A., Gouhier, T. C., Hacker, S. D., Chan, F., and Nielsen, K. J. (2015). Are meta-ecosystems organized hierarchically? A model and test in rocky intertidal habitats. Ecol. Monogr. 85, 213-233. doi: 10.1890/14-0113.1

Merriam, G. (1984). "Connectivity: a fundamental ecological characteristic of landscape pattern," in 1st International Seminar on Methodology in Landscape Ecological Research and Planning, eds J. Brandt and P. Agger (Roskilde: Roskilde University Centre).

Millenium Ecosystem Assessment (2005). Millennium Ecosystem Assessment: Living Beyond Our Means-Natural Assets and Human Well-Being. Washington, DC: World Resources Institute.

Mitchell, M. G. E., Suarez-Castro, A. F., Martinez-Harms, M., Maron, M., McAlpine, C., Gaston, K. J., et al. (2015). Reframing landscape fragmentation's effects on ecosystem services. Trends Ecol. Evol. 30, 190-198. doi: $10.1016 /$ j.tree.2015.01.011

Muñoz, J., Felicísimo, Á. M., Cabezas, F., Burgaz, A. R., and Martínez, I. (2004). Wind as a long-distance dispersal vehicle in the Southern Hemisphere. Science 304, 1144-1147. doi: 10.1126/science. 1095210

Murray, F., Widdicombe, S., McNeill, C. L., and Douglas, A. (2017). Assessing the consequences of environmental impacts: variation in species responses has unpredictable functional effects. Mar. Ecol. Prog. Ser. 583, 35-47. doi: 10.3354/meps12358

Needham, H. R., Pilditch, C. A., Lohrer, A. M., and Thrush, S. F. (2011). Contextspecific bioturbation mediates changes to ecosystem functioning. Ecosystems 14, 1096-1109. doi: 10.1007/s10021-011-9468-0

Norkko, A., Villnäs, A., Norkko, J., Valanko, S., and Pilditch, C. (2013). Size matters: implications of the loss of large individuals for ecosystem function. Sci. Rep. 3:2646. doi: 10.1038/srep02646

Pilditch, C. A., Valanko, S., Norkko, J., and Norkko, A. (2015). Post-settlement dispersal: the neglected link in maintenance of soft-sediment biodiversity. Biol. Lett. 11:20140795. doi: 10.1098/rsbl.2014.0795

Polis, G. A., Anderson, W. B., and Holt, R. D. (1997). Toward an integration of landscape and food web ecology: the dynamics of spatially subsidized food webs. Annu. Rev. Ecol. Syst. 28, 289-316. doi: 10.1146/annurev.ecolsys.28.1.289

Selkoe, K. A., Aloia, C. C., Crandall, E. D., Iacchei, M., Liggins, L., Puritz, J. B., et al. (2016). A decade of seascape genetics: contributions to basic and applied marine connectivity. Mar. Ecol. Prog. Ser. 554, 1-19. doi: 10.3354/meps11792

Smit, B., Burton, I., Klein, R. J., and Wandel, J. (2000). "An anatomy of adaptation to climate change and variability," in Societal Adaptation to Climate Variability and Change, eds S. M. Kane and G. W. Yohe (Dordrecht: Springer), 223-251.

Smyth, A. R., Geraldi, N. R., and Piehler, M. F. (2013a). Oyster-mediated benthicpelagic coupling modifies nitrogen pools and processes. Mar. Ecol. Prog. Ser. 493, 23-30. doi: 10.3354/meps10516

Smyth, A. R., Thompson, S. P., Siporin, K. N., Gardner, W. S., McCarthy, M. J., and Piehler, M. F. (2013b). Assessing nitrogen dynamics throughout the estuarine landscape. Estuaries and coasts 36, 44-55. doi: 10.1007/s12237-012-9554-3

Snelgrove, P. V., Thrush, S. F., Wall, D. H., and Norkko, A. (2014). Real world biodiversity-ecosystem functioning: a seafloor perspective. Trends Ecol. Evol. 29, 398-405. doi: 10.1016/j.tree.2014.05.002

Solan, M., Cardinale, B. J., Downing, A. L., Engelhardt, K. A., Ruesink, J. L., and Srivastava, D. S. (2004). Extinction and ecosystem function in the marine benthos. Science 306, 1177-1180. doi: 10.1126/science.1103960

Spiecker, B., Gouhier, T. C., and Guichard, F. (2016). Reciprocal feedbacks between spatial subsidies and reserve networks in coral reef meta-ecosystems. Ecol. Appl. 26, 264-278. doi: 10.1890/15-0478

Thrush, S., and Dayton, P. K. (2002). Disturbance to marine benthic habitats by trawling and dredging: implications for marine biodiversity. Annu. Rev. Ecol. Syst. 33, 449-473. doi: 10.1146/annurev.ecolsys.33.010802.150515

Thrush, S. F., Cummings, V. J., Dayton, P. K., Ford, R., Grant, J., Hewitt, J. E., et al. (1997). Matching the outcome of small-scale density manipulation experiments with larger scale patterns: an example of bivalve adult/juvenile interactions. J. Exp. Mar. Biol. Ecol. 216, 153-169. doi: 10.1016/S0022-0981(97)00094-4 
Thrush, S. F., Gray, J. S., Hewitt, J. E., and Ugland, K. I. (2006). Predicting the effects of habitat homogenization on marine biodiversity. Ecological Applications 16, 1636-1642. doi: 10.1890/1051-0761(2006)016[1636:PTEOHH]2.0.CO;2

Thrush, S. F., Hewitt, J. E., Kraan, C., Lohrer, A. M., Pilditch, C. A., and Douglas, E. (2017). Changes in the location of biodiversity-ecosystem function hot spots across the seafloor landscape with increasing sediment nutrient loading. Proceedings of the Royal Society B 284:20162861. doi: 10.1098/rspb. 2016.2861

Woodin, S. A., Wethey, D. S., and Volkenborn, N. (2010). Infaunal hydraulic ecosystem engineers: cast of characters and impacts. Integr. Comp. Biol. 50, 176-187. doi: 10.1093/icb/icq031
Conflict of Interest Statement: The authors declare that the research was conducted in the absence of any commercial or financial relationships that could be construed as a potential conflict of interest.

Copyright (c) 2018 Hillman, Lundquist and Thrush. This is an open-access article distributed under the terms of the Creative Commons Attribution License (CC BY). The use, distribution or reproduction in other forums is permitted, provided the original author(s) and the copyright owner(s) are credited and that the original publication in this journal is cited, in accordance with accepted academic practice. No use, distribution or reproduction is permitted which does not comply with these terms. 